\title{
An Acoustic Archival Tag for Long-Range Tracking Of Small Fishes
}

\author{
Fischer $\mathrm{G}^{1^{*}}$ and Rossby $\mathrm{T}^{2}$ \\ Department of Electrical Engineering, University of Rhode Island, USA \\ Graduate School of Oceanography, University of Rhode Island, USA
}

Submission: December 20, 2017; Published: April 26, 2018

Corresponding author: Fischer G, Department of Electrical Engineering, University of Rhode Island, Kingston RI 02881, USA, Email: fischer@uri.edu

\section{Abstract}

This mini review describes the development of an acoustic tag for long-range (tens to hundreds of kilometers) tracking of small fishes or other marine animals. Tracking is achieved by standard RAFOS triangulation using the arrival times of unique sound signals emitted by moored sources. The tag also records temperature and pressure. All functions of the tag are controlled by an application specific microchip. The collected acoustic and sensor data are stored in a non-volatile memory. A cylindrical hydrophone of $25.4 \mathrm{~mm}$ length and $10.7 \mathrm{~mm}$ diameter also serves as housing for all electronic components. Power is provided by 2 button cell batteries, which enable an active tag lifetime of approximately two years.

\section{Introduction}

Much has been learned about the behavior of fishes during the past few decades through various kinds of data storage tags (DSTs), which were attached either externally to the back of the fish, or subcutaneously (e.g. Metcalfe [1], Block [2]). By recording in-situ physical parameters such as temperature, depth and light intensity, the geographical position can be inferred on the basis of retrospective analysis of known hydrographic features of the animal's environment or light level for surface species. However, such retrospective positioning is invariably imprecise because physical features may vary only slightly (horizontally, and vertically in higher latitudes) or be poorly known (at least for purposes of retrospective positioning). During the first decade of the new millennium, a new technology emerged, which allowed equipping the tags with compact high frequency acoustic transmitters, each transmitting a unique ID code. When a fish tagged with such a transmitter passed within the acoustic range of a moored stationary receiver, a record of that event was kept. While fish cannot be tracked continuously this way, this widely used technology provided valuable insight into the overall range and timing of their movements [3].

To track submerged objects over much longer distances, Rossby [4] pioneered a new approach more than 30 years ago with his SOFAR floats, that passively listened for scheduled acoustic transmissions from anchored sound sources (Rossby [5], whose narrow-band emissions, centered at $260 \mathrm{~Hz}$, could be detected tens to hundreds of kilometers away depending on the physical conditions of the sound channel. The selected $260 \mathrm{~Hz}$ range renders signal absorption insignificant and avoids most of the lowfrequency ambient noise Urick [6], Wenz [7]. Each RAFOS float keeps a record of the arrival times of the precisely timed sound signatures. The source distance can then retroactively be inferred by multiplying the travel time of each sound signature by its known propagation speed.

\section{The Fish Tag}

Thanks to the continuing reduction of the transistor dimensions in microelectronic circuits (Moore's Law), it is now possible to implement the complex acoustic arrival time detector of a RAFOS float on a tiny microchip. While in its most active mode when the tag is searching for sound signatures, the chip dissipates approximately $70 \mu \mathrm{W}$, but the stand-by power is not more than $4 \mu \mathrm{W}$. Assuming a realistic duty cycle of $10 \%$ (e.g. searching for sound signatures for 6 minutes every hour), the average power dissipation amounts to just $10-11 \mu \mathrm{W}$. Two 1.5 -volt button cell batteries of $80 \mathrm{mAh}$ capacity can thus keep the system running for more than 2 years. The microchip also houses a thermal sensor as well as a pressure sensor interface to assess depth. The sensors utilized in the fish tag yield a resolution of $0.05{ }^{\circ} \mathrm{C}$ and approximately 0.7 PSI $(\sim 0.5 \mathrm{~m})$, respectively. If so desired, pressure and temperature can be sampled more frequently than searching for sound signatures. A more detailed description of the chip's features and its design can be found in reference Fischer [8].

Accurate timing is critically important in any time-of-flight based positioning system. Since the fish tag's energy capacity is severely limited, it uses a low power commercial watch crystal oscillator 
circuit as the clock source. To avoid severe clock deviations, the fish tag timer employs a digital correction unit, which allows adjusting for offset errors stemming from the manufacturing process and compensating for the expected temperature deviations. The 6-bit digital correction scheme limits timing errors to $\pm 0.95 \mathrm{ppm}$ or \pm 0.6 seconds per week. The remaining clock deviations can be mitigated by utilizing the travel time differences from three source to determine the position hyperbolically. One can then retroactively determine the clock correction needed to obtain the right travel time [9].

The assembly of the tag is a relatively straightforward matter. The custom microchip is surface mounted on a tiny printed circuit board (PCB) together will all other electronic components, i.e., the watch crystal oscillator, the nonvolatile memory chips and 3 filter capacitors. This PCB is only $8 \mathrm{~mm}$ wide and fits tightly inside the hydrophone cylinder, which also serves as the tag's housing. The circular pressure sensor board is attached perpendicular to the PCB and forms one of the two end plates of the cylindrical tag. Figure 1 depicts a RAFOS sound source together with one of the $4 \mathrm{~cm}$ long prototype tags without its final polyurethane coat.

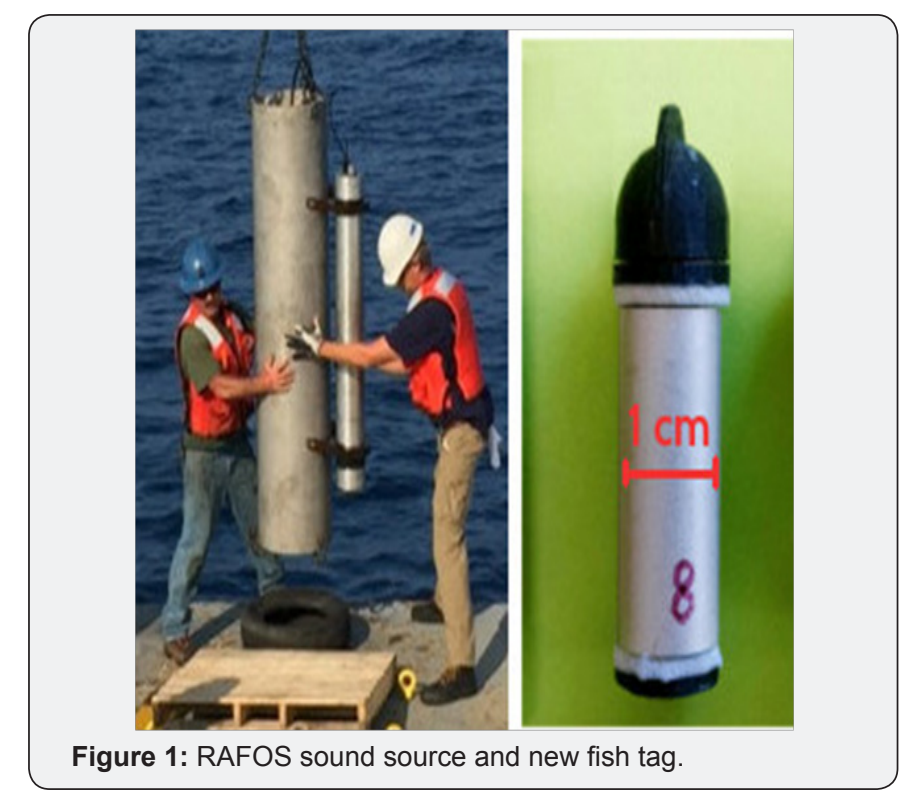

\section{Field Test Results}

A series of field tests have been conducted during the course of this project to validate the performance of the tag in its various stages. The first was a preliminary test designed to evaluate the critically important analog preamplifier and the potential tracking range. In this experiment, source and receiver were kept below the surface mixed layer at $\sim 40$ and $30 \mathrm{~m}$, respectively, on the New England shelf south of Nantucket. At a distance of $70 \mathrm{~km}$ from the acoustic source, the records revealed a robust in-band signal-tonoise ratio of approximately $6 \mathrm{~dB}[10]$.

Encouraged by the positive early test results, the project continued. But it was not until this past summer that first complete prototype tags became available. This paved the way for a more comprehensive test conducted approximately $50 \mathrm{~km}$ south of the Mississippi delta in the Gulf of Mexico. The logistics of this experiment were simple. The tags were attached to the ends of two $30 \mathrm{~m}$ long ropes, which in turn were tied to 2 surface drifters equipped with GPS trackers. The sound source was kept on the host vessel, the Endeavor, and lowered repeatedly to a depth of approximately $25 \mathrm{~m}$ from the Starboard side at various distances starting at $\sim 130 \mathrm{~km}$.

The submerged tags recorded an almost uniform water temperature around $27{ }^{\circ} \mathrm{C}$ during the 40 -hour test period. This warm surface layer provided for less than ideal acoustic conditions, since it bends the acoustic energy away from the surface. But a thin fresh water lens of Mississippi origin created a shallow surface sound channel such that transmissions could be detected as far as $60 \mathrm{~km}$ away. The source level was measured with a calibrated hydrophone to be $180 \mathrm{~dB}$ re $1 \mu \mathrm{Pa}$ at $1 \mathrm{~m}$. It was therefore no surprise that none of the tags detected a signal emitted from any of the three farthest source sites located $72-130 \mathrm{~km}$ away.

4-8 sound signatures were emitted at each source site. The recordings revealed a remarkably small spread in signal propagation times, $0.053-0.132$ seconds. This corresponds to a spatial uncertainty range of not more than $200 \mathrm{~m}$.

\section{Conclusion}

The presented fish tag, with a length of approximately $4 \mathrm{~cm}$ similar in size to other archival tags, operates according to standard RAFOS tracking principles: it detects and records the arrival times of signals transmitted from moored sound sources. Navigational accuracy is determined by how well clock errors in the tag can be controlled, but can be kept quite small thanks to knowing total drift error and temperature of the crystal clock during mission. The two main drawbacks of the presented tagging technology are the cost for the sound infrastructure and the need to retrieve the tag to upload the archived data. At a future time, we will explore how to avoid the second drawback by adapting the tag to a miniature satellite transmitter and a release mechanism, which allows the device to float to the surface at the end of mission. The added bulk means this technology will be best suited to larger species.

\section{Acknowledgement}

This work has been supported by subsequent NSF/OTIC awards 0326907, 1061083 and 1435698. Funding by the Rhode Island Endeavor Program for two cruises is gratefully acknowledged.

\section{References}

1. Metcalfe JD, Arnold GP, Holford BH (1994) The migratory behavior of plaice in the North Sea as revealed by data storage tags. ICES CM, pp. 13.

2. Block BA, Dewar H, Blackwell SB, Williams TD, Prince ED, et al. (2001) Migratory movements, depth preferences, and thermal biology of Atlantic bluefin tuna. Science 293(5533): 1310-1314.

3. VEMCO (2009) VEMCO Acoustic Telemetry - New User Guide, DOC004934-01, pp. 1-22.

4. Rossby HT, Dorson D, Fontaine J (1986) The RAFOS System. J Atmos Oc Tech 3: 672-679. 
5. Rossby HT, Ellis J, Webb DC (1993) An efficient Sound Source for widearea RAFOS Navigation. J Atmos Oc Tech 10: 397-403.

6. Urick RJ (1983) Principles of underwater sound. Peninsula Publishing, Los Altos, California, USA, pp. 423.

7. Wenz GM (1962) Acoustic ambient Noise in the Ocean. J Acoustic Soc Amer 34(12): 1946-1956.

8. Fischer G, Rossby T, Moonan DW (2017) A miniature acoustic Device for Tracking small marine Animals or submerged Drifters. Journal of Atmospheric and Oceanic Technology 34(12): 2601-2612.

9. Blanchard WF (1991) Air navigation systems Chapter 4. Hyperbolic airborne radio navigation aids - A navigator's view of their history and development. J Navig 44(3): 285-315.

10. Fischer G, Lee S, Obara M, Kasturi P, Rossby HT et al. (2006) Tracking Fishes with a microwatt acoustic Receiver - An archival Tag Development. IEEE J Oc Eng 31(4): 975-986.

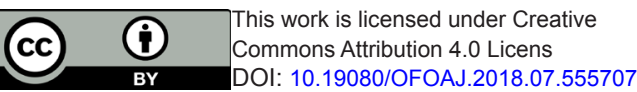

Your next submission with Juniper Publishers will reach you the below assets

- Quality Editorial service

- Swift Peer Review

- Reprints availability

- E-prints Service

- Manuscript Podcast for convenient understanding

- Global attainment for your research

- Manuscript accessibility in different formats

( Pdf, E-pub, Full Text, Audio)

- Unceasing customer service

Track the below URL for one-step submission https://juniperpublishers.com/online-submission.php 